DOI 10.37882/2223-2982.2020.06.39

\title{
МЕТОДИКА ПРОВЕДЕНИЯ БЫСТРЫХ ИССЛЕДОВАТЕЛЬСКИХ ПРОЕКТОВ В ШКОЛЕ
}

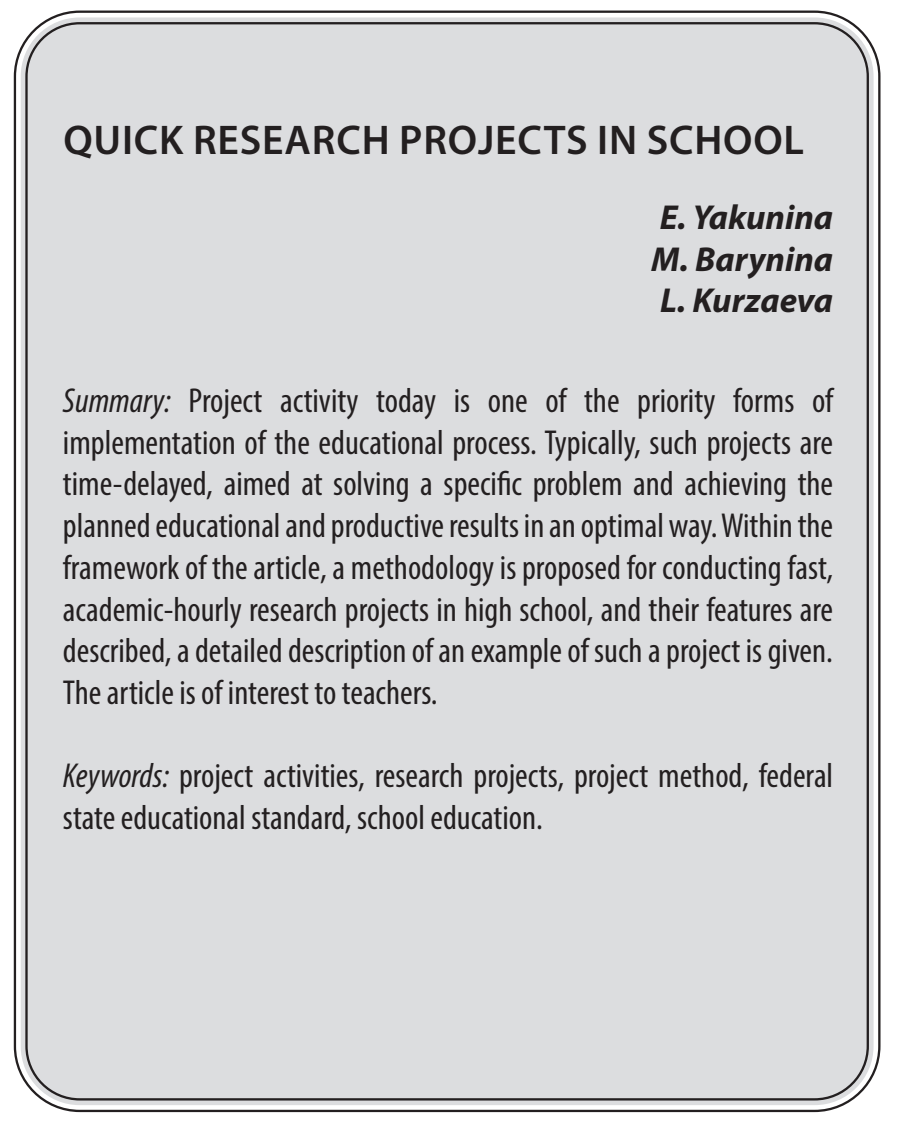

$\mathrm{B}$ последние годы все больше укрепляются позиции проектной и исследовательской деятельности в школьном образовании. Актуальность введения таких видов деятельности определяется их многофункциональной и многоцелевой направленностью, беспрепятственным внедрением в целостный образовательный процесс, не нарушая его, а наоборот, позволяя обучающимся наряду с овладением системными базовыми знаниями и ключевыми компетенциями, всесторонне развивать личность.

Здесь следует отметить, что оба понятия, «проектная деятельность» и «исследовательская деятельность» связаны с мыслительной деятельностью, а именно: проектирование - связно с ее началом и реализацией идеи, исследование - с поиском и пониманием действительного. Помимо этого, проектирование и исследование имеют непосредственное отношение к прогностической деятельности. Все это в совокупности делает проектную и исследовательскую деятельность одним из важнейших факторов развития мышления, интеллекта и креативности обучающегося.
Якунина Елизавета Константиновна

ФГБОУ ВО «Магнитогорский государственный технический университет им. Г.И. Носова»

FoxDieKrieger@mail.ru

Барынина Марина Витальевна

ФГБОУ ВО «Магнитогорский государственный технический университет им. Г.И. Носова» marina.barynina@mail.ru

Курзаева Любовь Викторовна К.n.н., доцент, ФГБОУ ВО «Магнитогорский государственный технический университет им. Г.И. Носова» Ikurzaeva@mail.ru

Аннотация: Проектная деятельность сегодня является одной из приоритетных форм реализации образовательного процесса. Обычно такие проекты пролонгированы во времени, направленны на решение конкретной проблемы и достижение оптимальным способом запланированных образовательных и продуктовых результатов. В рамках статьи предлагается методика проведения быстрых, рассчитанных на академический час, исследовательских проектов в средней школе, а также описываются их особенности, приводится развернутое описание примера такого проекта. Статья представляет интерес для педагогических работников.

Ключевые слова: проектная деятельность, исследовательские проекты, метод проектов, федеральный государственный образовательный стандарт, образование в школе.

В соответствие с Федеральным государственным образовательным стандартом среднего общего образования, является необходимым развитие у обучающихся «самостоятельности планирования и осуществления учебной деятельности и организации учебного сотрудничества с педагогами и сверстниками, построение индивидуальной образовательной траектории» [1], чему и соответствуют основные цели применения проектной деятельности, а именно:

- вовлечь каждого обучающегося в активный познавательный, творческий процесс;

- научить представлять результаты своей работы, отстаивать свои взгляды на выбор методов и материалов, необходимых для осуществления творческих замыслов;

- научить применять свои знания в новых условиях;

- сформировать универсальные учебные действия;

- воспитать у детей интерес к творческому взаимодействию при совместной работе;

- научить ориентироваться в информационном пространстве.

Проблема проектной деятельности не является аб- 
солютно новой в педагогической теории и практике. Философско-методологические основы организации проектной деятельности учащихся раскрыты в трудах отечественных и зарубежных педагогов конца XIX - начала XX веков (Д. Дьюи, В. Килпатрика, Е. Коллингса, ГТ.ГГ. Блонского, В.П. Вахтерова, Б.В. Игнатьева, Е.Г. Кагарова, М.В. Крупениной, Л.Э. Левина, С.Т. Шацкого, В.Н. Шульгина и др.), а также в работах современных ученых (А.Н. Джуринского, И.И. Ляхова, Ю.В. Громыко, В.И. Слободчикова, А.В. Хуторского и др.). В настоящее время проектная деятельность учащихся является предметом историко-теоретических исследований в работах Р.Б. Вендровской, А.Э. Коробовой, Е.Ю. Рогачевой, Н.В. Турчиной и др. Психологии проектной деятельности школьников посвящена докторская диссертация Н.В. Матяш. Со стороны педагогических закономерностей проектная деятельность школьников рассмотрена в исследованиях В.В. Гузеева, И.А. Дралюк, И.А. Зимней, Н.Б. Крыловой, Н.Ю. Пахомовой, Е.С. Полат, В.Д. Симоненко, И.Д. Чечель и др. Все больше появляется научных работ, посвященных использованию проектной деятельности при изучении различных школьных учебных дисциплин.

Однако, несмотря на то, что сегодня проектная деятельность широко применяется в общеобразовательных школах, точных представлений о том, какой она должна быть, до сих пор не сформировано. Мнения разнятся и одни учителя в качестве проекта видят написание учеником реферата или выступление с презентацией по теме, другие требуют творческое выполнение стандартного задания (создание стенгазет, ментальных карт или даже сценических номеров по теме), третьи предлагают действительно серьезные исследования с последующей защитой по принципу дипломной работы. В первую очередь такая путаница связана с широкой трактовкой самого понятия «проект», поэтому необходимо четко уяснить, что означает термин «проект», определить его основные признаки и отличия от других видов самостоятельной работы обучающихся.

Первостепенно следует разграничивать понятия «исследовательская работа» и «проект».

Исследовательская работа - работа, связанная с решением творческой, исследовательской задачи с заранее неизвестным результатом. Такая работа имеет большое сходство с проектом. Однако в данном случае исследование - это лишь этап проектной работы.

На сегодняшний день, проект понимают как идею, которой субъект может и вправе распоряжаться как своей мыслью. Касательно учебного процесса, проектом называют работу, направленную на решение конкретной проблемы, на достижение оптимальным способом заранее запланированного результата; может включать элементы докладов, рефератов, исследований и иных видов самостоятельной работы обучающихся, но только как способов достижения результата проекта.

Проектная деятельность обучающихся - это совместная учебно-познавательная, творческая или игровая деятельность обучающихся, имеющих общую цель, методы, способы деятельности, направленные на достижение общего результата. Наиболее важным условием является наличие заранее выработанных представлений о конечном образовательном результате, этапах проектирования и реализации проекта, а также его осмыслении и рефлексии результатов деятельности.

Проектная деятельность способствует развитию навыков рефлексии, коммуникации и сотрудничества, формирует управленческие и презентационные умения, а также незаменима в становлении исследовательских умений.

Участвовать в проекте или исследовании могут обучающиеся разного возраста, уровня подготовленности и развития.

Обычно проекты - это довольно трудозатратный процесс, длящийся не одну неделю или даже месяц. Они требуют много времени и внимания как от обучающихся, так и от учителей. Мы предлагаем обратить внимание на такую методику, как организация и проведение «быстрых» проектов в школе. Цель такой методики - провести внеклассное занятие-проект за один академический час.

Проектные уроки строятся по следующему плану:

1. Формулировка проблемной ситуации.

2. Формулировка проблемы.

3. Формулировка цели (планируемого результата).

4. Формулировка задач (шаги для достижения цели).

5. Организация работу в группах. Определение регламента работы.

6. Презентация.

7. Рефлексия обучающихся.

8. Оценка обучающихся.

Такие короткие «быстрые» проекты обладают рядом преимуществ:

- позволяет поддерживать концентрацию внимания и активность на протяжении всего занятия;

- позволяют быстрее и эффективнее формировать и развивать универсальны учебные действия обучающихся, на основе которых формируются проектные умения и проектная деятельность в целом;

- значительно повышается мотивация учебной деятельности на предметных уроках, за счет того, что обучающиеся видят результат своей работы по истечению одного академического часа;

- создаются необходимые условия для применения знаний на практике. 
«Быстрые» проекты могут выступать в самых разных формах: Задания могут звучать следующим образом: создать памятку для туристов (английский язык, история, география), составить презентацию, создать рекламу, кластер, постер, книгу, газету, взять интервью и пр.

В качестве примера приведем разработку внеурочного занятия, в рамках которого реализуется исследовательский проект на основе эксперимента.

Занятие рассчитано на учащихся 8-го класса, целью которых будет изучение свойств QR-кода.

При проектировании внеурочного занятия были определены следующие задачи:

- Обучающие: ознакомиться с понятием QR-кода, научить анализировать текст задачи, разбивать решение задачи на этапы, применять на практике полученные знания, научить проводить эксперимент.

- Развивающие: научить анализировать полученные результаты, сравнивать, делать выводы.

- Воспитательные: воспитать творческий подход к труду, аккуратность, ответственность.

В качестве ожидаемых результатов мы видим то, что в ходе урока ученики получат базовые знания о QR-коде и его составляющих, приобретут практические навыки в решении задачи путем разбиения процесса решения на этапы, в том числе: в проведении эксперимента и анализе полученных результатов, закрепят знания о назначении и целесообразности применения QR-кода, закрепят полученные знания на практике.

Необходимое оборудование для проведения внеклассного занятия включает ПК, мультимедийная электронная доска, Microsoft Power Point, смартфоны с установленными программами для сканирования QR-кодов, раздаточный материал, ножницы, маркеры, емкость с водой.

Занятие делится на три этапа. На первом этапе учитель приветствует учащихся. Настраивает на работу. Демонстрирует слайд с изображением QR-кода и спрашивает учеников, знают ли они, что это такое. Ученики в свою очередь делают предположения, дают ответы.

Далее учитель уточняет определения учеников и дает базовые понятия о QR-коде и краткую историческую справку. Рассказывает о причинах его популярности. Однако не дает никакой детальной информации об устройстве QR-кода и принципах его работы.

Также учитель может спросить учеников, где они уже встречались с QR-кодами, и в каких сферах жизни их можно применять. При необходимости дополняет ответы учеников. Спрашивает, считают ли ученики, что такой вид хранения информации как QR-код практичен и долговечен, что с ним может произойти? Что может нарушить считываемость кода? Записывает ответы учеников на доске. Желательно, чтобы ученики назвали такие факторы как влага, пыль, физическое воздействие, грязь и т.п.

Учитель наталкивает учеников на сомнение, повлияют ли эти факторы на распознавание QR-кода или нет. Предлагает провести эксперимент.

На втором этапе учитель просит учеников разделиться на три команды, каждой из которых предстоит провести свой эксперимент.

Участники каждой группы между собой самостоятельно определяют какой способ воздействия на QRкоды они собираются изучить, придумывают четыре варианта интенсивности воздействия на QR-код выбранным фактором и заполняют таблицу (например, таблица $1)$.

В нашем случае команды разделились следующим образом: участники первой группы изучают воздействие воды, участники второй - устойчивость к повреждениям, третья команда решила проверить считываемость кода при различном уровне загрязнения (закрашивания).

Таблица 1.

Пример таблицы эксперимента

Команда 1 (воздействие влаги)

Ход эксперимента

Слегка смочить QR-код водой

Намочить QR-код полностью

Подержать QR-код под водой некоторое время

Подержать QR-код под водой и смазать изображение

Команда 2 (физические повреждения)

Ход эксперимента

Результат (+/-)

Отрезать уголок от QR-кода

Вырезать QR-код, не оставляя белой рамочки, просканировать на белом фоне

Вырезать QR-код, не оставляя белой рамочки, просканировать на черном фоне

Вырезать середину из QR-кода (диаметр 1 см)

Команда 3 (загрязнения)

Ход эксперимента Результат (+/-)

Закрасить по черным участкам QR-кода

Закрасить середину QR-кода

Закрасить большие квадраты в углах QR-кода

Закрасить белые участки QR-кода 
После завершения работы ученики совместно с учителем обсуждают полученные результаты, предполагают, почему в том или ином случае код не сканировался, приходят к выводу, что дело в устройстве QR-кода. Пытаются вывести закономерности.

На третьем этапе учитель обобщает мысли учащихся, поясняет, почему в определенных случаях невозможно было отсканировать QR-код, показывает схему устройства QR-кода.

В итоге ученики должны усвоить, что:

- Большие черные квадраты выполняют функцию поискового узора. По ним сканер определяет положение кода. При отсутствии хотя бы одного из них код сканироваться не будет.

- Прилежащие к поисковому участку области также важны, они содержат код маски уровня коррекции и код версии. Поэтому эти места должны быть хорошо различимы.

- Чтобы код считывался, он должен быть хорошо различим. Это касается и боковых граней, поэтому белая (светлая) рамочка обязательна.

- Информация, содержащаяся в центре кода - избыточна. Чем позднее версия генератора кода, тем эта область больше.

Учитель также демонстрирует примеры нестандартHых QR-кодов, показывающих, что при учете основных принципов, QR-коды можно изменять, перекрашивать, размещать изображения поверх частей кода.

Теперь, когда ученики выяснили основной принцип работы QR-кода и усвоили необходимые знания, учитель предлагает им самостоятельно украсить предложенный на доске код, чтобы он был красивым, ярким, но считываемым.

Таким образом учащиеся не только самостоятельно добывают знания о новом объекте и сами, экспериментальным путем выявляют его принцип действия, но и закрепляют полученные знания на практике.

Основная идея «быстрых» проектов заключается в том, чтобы перенести акцент с различного вида упражнений на активную мыслительную деятельность в ходе совместной творческой работы.

Проектная технология позволяет учителю работать над развитием у обучающихся умений учебной деятельности: выполнять проектные работы, создавать баланс индивидуальной и групповой работы на уроке, проводить анализ деятельности, развивать умения работать в коллективе и организовывать свою работу на всех этапах обучения (от мини-проектов в начальной школе до стратегий учебы).

Выполнение проектов дает возможность реализовать основные идеи стандарта нового поколения.

\section{ЛИТЕРАТУРА}

1. 06 утверждении Федерального государственного образовательного стандарта основного общего образования: приказ от 17.12 .2010 № 1897 [Электронный ресурc]: URL: https://fgos.ru/

2. Брыкова 0.В. Проектная деятельность в учебном процессе / О.В. Брыкова, Т.В. Громова М.: Чистые пруды, 2006. - 32с.

3. Бычков А.В. Метод проектов в современной школе. - М.: Изд-во МГУ, 2014. 48с.

4. Калиткина, Е.В. Организация проектной деятельности младших школьников [Электронный ресурс] // Молодой ученый. — 2019. — № 1 (239). — C. 168-170. — URL: https://moluch.ru/archive/239/55361/ (дата обращения: 14.04.2020).

5. Ксензова, Г.Ю. Руководство по внеурочной проектной деятельности учащихся: методические рекомендации : Москва: Пед. 0-во России, 2016. - 77 с.

6. Лаврова В.П., Мухоплева А.М. Роль проектной деятельности в разностороннем развитии учащихся [Электронный ресурс] // Научно-методический электронный журнал «Концепт». - 2017. - Т. 11. - С. 123-124. - URL: http://e-koncept.ru/2017/770175.htm.

7. Матяш Н.В. Проектный метод обучения в системе технологического образования. // Педагогика. 2000. - № 4. - С. 96-101.

8. Матяш Н.В. Психология проектной деятельности школьников: Дис. . д-ра психологических наук: Брянск, 2000. — 385с.

9. Метод проектов в учебном заведении // Педагогическая лоция. Специальное приложение к журналу «Лицейское и гимназическое образование», 2007. $96 c$.

10. Мингалева, Н.И. Организация проектной деятельности школьников: опыт работы // Культура и образование: новые вызовы и перспективы: материалы II Всероссийской научно-практической интернет-конференции, г. Кемерово, 04-28 апреля 2016. - Кемерово, 2016. - С.34-38.

11. Никитина И.В. Проектная деятельность как средство организации образовательной среды: Дис. канд. пед. наук. Москва, 2007. -213с.

12. Новикова Т. Проектные технологии на уроках и во внеурочной деятельности // Народное образование, 2000. №7. - С. 151-157.

13. Пилюгина Н.А. Проектный метод - один из способов реализации компетентностно-ориентированного обучения // Старшая школа. - 2015. - №1. - С. 44-46.

14. Поливанова К.Н. Проектная деятельность школьников: пособие для учителя. М.: Просвещение, 2008. - 192с.

15. Романовская М.Б. Метод проектов в учебном процессе. Методическое пособие / М.: Центр «Педагогический поиск», 2006. — 160с. 
16. Сиденко А.С. Метод проектов: теория и практика применения. //Завуч. 2003. — № 6. - С. 96-111.

17. Чечель И.Д. Исследовательские проекты в практике обучения // Практика административной работы в школе. 2003. - № 6. -С. 24 - 29.

18. Шамова Т.И. Избранное. М.: 000 «Центральное издательств0», 2014. - 320с.

\section{๑) Якунина Елизавета Константиновна (FoxDieKrieger@mail.ru), Барынина Марина Витальевна (marina.barynina@mail.ru), Курзаева Любовь Викторовна (Ikurzaeva@mail.ru).}

Журнал «Современная наука: актуальные проблемы теории и практики»

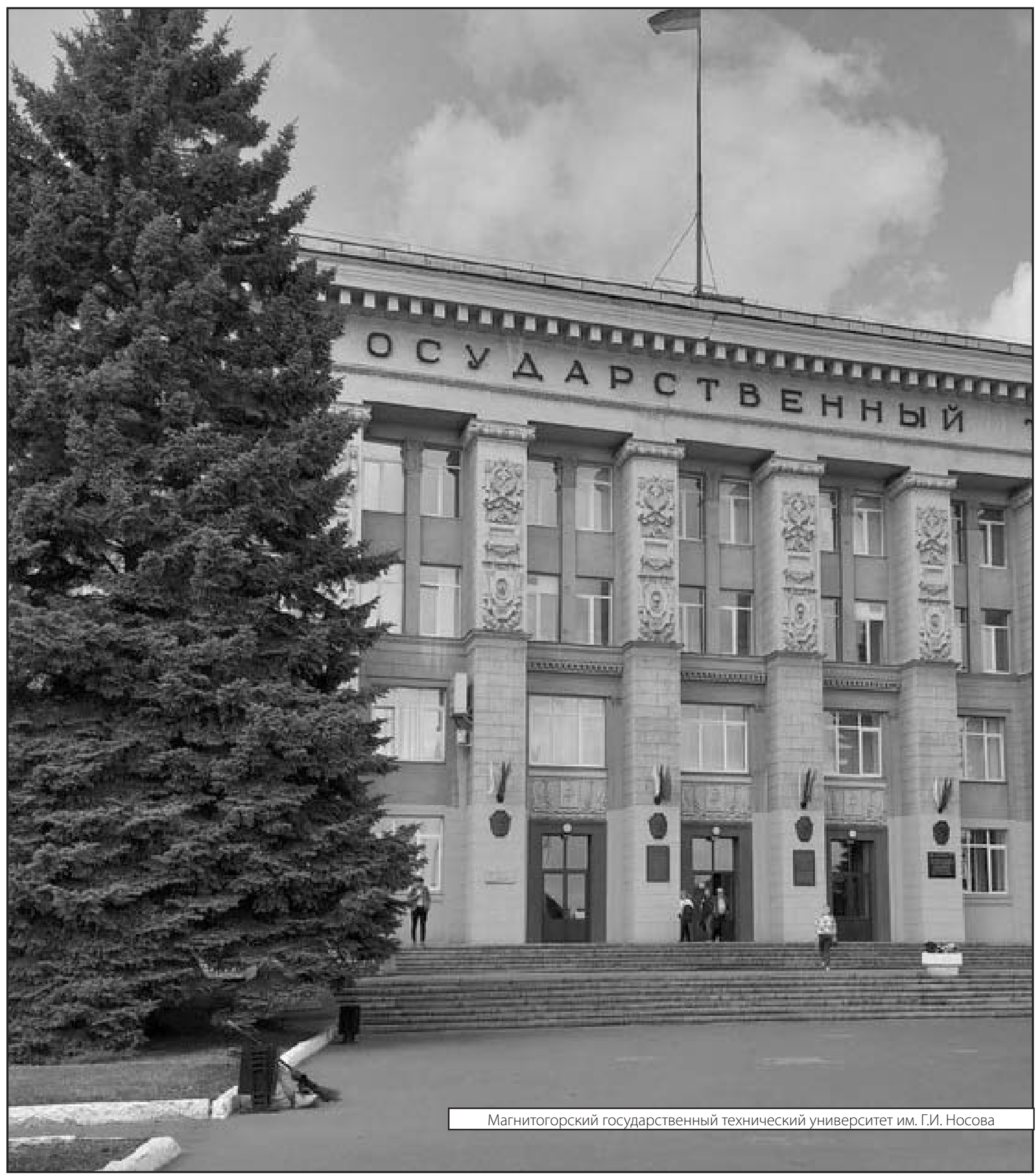

